\title{
TOM DOUGHERTY(D)
}

\section{CONSENT, COMMUNICATION, AND ABANDONMENT}

\author{
(Accepted 19 March 2019)
}

\begin{abstract}
According to the Behavioral View of consent, consent must be expressed in behavior in order to release someone from a duty. By contrast, the Mental View of consent is that normatively efficacious consent is entirely mental. In previous work, I defended a version of the Behavioral View, according to which normatively efficacious 'consent always requires public behavior, and this behavior must take the form of communication in the case of high-stakes consent'. In this essay, I respond to two arguments by proponents of the Mental View. First, Larry Alexander, Heidi Hurd and Peter Westen have argued that my view has mistaken implications concerning the culpability of different actors. I counter that my version of the view does not have these implications, as it leaves us free to draw moral and legal distinctions between different offences involving non-consensual behavior. Second, Larry Alexander and Kimberly Ferzan have argued for an analogy between consent and abandonment: on the grounds that the normative power to abandon resides in one's will, Alexander and Ferzan concludes consent does too. I counter that abandonment requires behavior, and call into question the assumption that the ethics of property have much to teach us about the ethics of sexual consent.
\end{abstract}

\section{INTRODUCTION}

If we're going to sanction criminals with loss of their liberty, then we had better have a justification for doing so. A plausible justification centers on the claim that they have committed offences that are proportionately objectionable from a moral point of view. ${ }^{1}$ Take that

\footnotetext{
${ }^{1}$ In addition, punishing people for committing so-called malum prohibitum offences may be justified on other grounds, e.g. that this punishment serves sufficiently useful functions at reasonable costs to others. For example, someone might be punished for selling medical drugs without a license, on the grounds that public safety is promoted by a practice of enforcing a rule against such sales. Thanks to Alec Walen for this point.

For helpful comments, I am grateful to Alec Walen and two anonymous reviewers. The research for this essay was financially supported by an Early Career Leadership Fellows Award from the Arts and Humanities Research Council, Council Reference: AH/N009533/1.
} 
idea seriously, and the philosophy of the criminal law becomes intertwined with moral philosophy. A clear example is the topic of sexual offences. On the assumption that the moral depravity of these offences is part of the justification for punishing those who commit them, philosophers of the criminal law should be interested in the question of what makes sexual misconduct morally wrong. A popular liberal approach to answering this question focuses on consent. Roughly, the thought is that imposing sexual contact on someone without her consent is a moral wrong that should be criminalized, but the state should take no interest in sex between consenting adults. If we accept all this, then we are led to the question of what constitutes morally valid sexual consent. Clearly, this consent needs to be suitably informed, competent and free from duress. But assuming those conditions are met, what does someone actually need to do in order to consent?

On this question, there are two main schools of thought. According to the Mental View, consent is entirely a mental phenomenon. Some have said that sexual consent involves intending that a sexual encounter takes place, or acquiescing to it. ${ }^{2}$ Others have said that sexual consent involves intending to forego a complaint against a boundary crossing, or deciding that a sexual contact is 'ok with me'. ${ }^{3}$ While the respective merits of each position deserve further consideration elsewhere, here we should focus on their common thread - the idea that consent resides entirely within one's will. That idea is denied by the other school of thought. According to the Behavioral View, consent requires some form of external behavior. For example, the requisite behavior might be a form of communication. One version of the Behavioral View holds that this behavior by itself could be sufficient for consent. Another version of the Behavioral View is that the behavior needs to be accompanied by an attitude, e.g. a decision to give consent.

In this essay, I will critically discuss two arguments that support the Mental View over the Behavioral View. The first argument is a critique of my defense of a version of the Behavioral View, in which

\footnotetext{
${ }^{2}$ For the former view, see Heidi Hurd. 'The Moral Magic of Consent', Legal Theory 2(2) (1996): 121146. For the latter view, see Peter Westen, The Logic of Consent (Ashgate: Ashgate Publishing, 2004).

${ }^{3}$ For the former view, see Larry Alexander, 'The Moral Magic of Consent II', Legal Theory 2(3) (1996): 165-174; Larry Alexander, 'The Ontology of Consent', Analytic Philosophy 55(1) (2014): 102-113. For the latter view, see Kimberly Kessler Ferzan, 'Consent, Culpability, and the Law of Rape', Ohio State Journal of Criminal Law 13(2) (2016): 397-439.
} 
I argued that 'morally valid consent always requires public behavior, and this behavior must take the form of communication in the case of high-stakes consent'. ${ }^{4}$ In response, Larry Alexander, Heidi Hurd and Peter Westen - henceforth, 'Alexander et al.' - have argued that my view has mistaken implications concerning the culpability of different actors. ${ }^{5}$ The second argument has been offered by Alexander and Kimberly Ferzan. ${ }^{6}$ They appeal to an analogy between consent and abandonment: on the grounds that the normative power to abandon resides in one's will, Alexander and Ferzan conclude consent does too. I will offer responses to each argument in turn.

\section{ARGUMENT 1: CONSENT AND CULPABILITY}

Our first argument is part of Alexander et al.'s critique of my defense of the Behavioral View of consent. Alexander et al. introduce a case of someone failing to communicate her desire to have sex with another person:

Wanted Sex. Sue wants Sam to have sex with her. Yet she is afraid that if she communicates that to him, he might think she is "easy" or "trashy" and ultimately reject a long-term relationship with her, a relationship she desires.

One night, Sam begins making sexual advances with Sue. Sue wants him to proceed, but she says nothing to encourage him and indeed resists him with some force at each step of the way. This resistance does not deter him, and ultimately they have sex.

Sue is delighted. Things worked out just as she had hoped. Sam had sex with her, but she was able to communicate that she was not consenting to it.

About this case, Alexander et al. allow that if 'Sam believed there was a significant risk that she was not consenting, then Sam acted culpably', and it may be that he could be appropriately punished e.g. for attempted sexual assault. But they maintain that 'Sam did not

\footnotetext{
${ }^{4}$ Tom Dougherty, 'Yes Means Yes: Consent as Communication', Philosophy and Public Affairs 43(3) (2015): 224-253, p. 227.

${ }^{5}$ Larry Alexander, Heidi Hurd, \& Peter Westen, 'Consent Does Not Require Communication: A Reply to Dougherty', Law and Philosophy 35(6) (2016): 655-660.

${ }^{6}$ Alexander, 'The Ontology of Consent'; Ferzan, 'Consent, Culpability, and the Law of Rape'.
} 
wrong Sue. He did not cross her moral boundary without her consent'.

Since the literature already contains several cases of agents not communicating their decisions to consent, and this literature shows that people do not share the same intuitions about these cases, positing yet another case is unlikely to move the debate forward. ${ }^{8}$ However, Alexander et al. do go on to offer a novel argument, which offers the potential of breaking new ground in the debate. This argument focuses on the implications of their view and my view for the framing of the criminal law. Let us suppose that in the Wanted Sex case, Sam believes that Sue has the requisite mental attitude for consent. ${ }^{9}$ On that assumption, Alexander et al.'s view would be that the criminal law should hold that Sam's act is not wrong, and that he is not culpable. ${ }^{10}$ But Alexander et al. hold that the criminal law should take the opposite view of someone who is imposing sexual activity on a person who lacks the attitude necessary for consent, while the actor is aware that she lacks this attitude. Here is a case that fits this template:

\footnotetext{
7 Alexander et al. 'Consent Does Not Require Communication', p. 656.

${ }^{8}$ In the same essay, Alexander et al. also argue against my view on the grounds that it gets the wrong results about a case that can be abbreviated as follows:

Pool Party. Jane intends to invite Jim to her party, but does not want to invite him herself. So Jane asks Ken to invite him. Ken instead tells Jim he is not welcome. Jim comes anyway.

This is an odd case to offer against the Behavioral View, given that Jane has engaged in public behavior that expresses her decision to invite Jim. It is also an odd case to offer against my defense of the Behavioral View, given that this defense allows that communication was not required for low-stakes consent. The case could only serve as a counterexample to versions of the Behavioral View that do not allow Jane's behavior to constitute consent. In any event, this strand of Alexander et al.'s critique also does little to advance the debate, given the debate's background. In its earliest phase, this debate involved philosophers offering hypothetical cases in which someone does not express her decision to give consent. These philosophers stated what they took to be the intuitive verdicts about whether this person validly consents, and argued that these verdicts supported their favored view in the debate. But as I noted, this did not help resolve the debate since 'the literature contains several examples of philosophers registering opposing intuitions about noncommunicated intentions to consent, sometimes concerning structurally analogous cases, and even about the very same case'. I concluded that 'there would appear to be room for reasonable disagreement at the level of intuition about these cases' and proposed that 'we must look elsewhere to move forward the debate'. Alexander et al. 'Consent Does Not Require Communication', p. 656; Dougherty, 'Yes Means Yes', pp. 230-231.

${ }^{9}$ This assumption does not affect the substance of Alexander et al.'s argument, which concerns the template for a case in which the agent truly believes that his sexual partner has the attitude necessary for valid consent, but has not communicated consent. Alexander et al. 'Consent Does Not Require Communication', p. 659. By making this assumption, we can both focus on a concrete case (rather than a template for a case) while simplifying the number of cases under discussion. I also take it that on the natural reading of the Wanted Sex case, the assumption is true.

${ }^{10}$ Where 'A' denotes the attitude necessary for consent, this case fits Alexander et al.'s template of 'A, and the defendant's belief that A'. They hold that for this possibility the criminal law should view there as being 'No wrong and no culpability'. Ibid., p. 659.
} 
Unwanted Sex. Teresa is not willing to have sex with Tony. Teresa does nothing to indicate that she is willing to engage in sexual intercourse with Tony. Tony realizes that Teresa is not willing to engage in sexual intercourse, and has not communicated that she is. Tony proceeds to engage in sexual intercourse with Teresa.

About a case like this, Alexander et al.'s view is that the criminal law should view Tony's act as wrong (in virtue of Teresa lacking the attitude necessary for consent) and it should view Tony as acting culpably (in virtue of being aware that Teresa lacks this attitude). Meanwhile, regarding the Wanted Sex case, on the assumption that Sam believes that Sue has the attitude necessary for consent, Alexander et al. would see Sam as non-culpable.

However, Alexander et al. argue that I am committed to seeing Tony and Sam as equally culpable. Alexander et al. assume that I would revise the criminal law so that 'consent to sex were defined as both an attitude and a communication'. ${ }^{11}$ Now in the Wanted Sex case, there has not been communication of consent. So Alexander et al. would infer that on my favored formulation of the criminal law, Sam has committed a wrongful act. Moreover, Sam is aware that Sue has not communicated consent. So they would infer that on my favored formulation of the criminal law, Sam acts culpably. ${ }^{12}$ Meanwhile, in the Unwanted Sex case, Teresa lacks the attitude necessary for consent, and has not communicated consent. Consequently, Alexander et al. would infer that my preferred criminal law would view Tony's act as wrong. Meanwhile, Tony is aware that Teresa lacks the attitude necessary for consent, and has not communicated consent. Consequently, Alexander et al. would infer that my preferred criminal law would view Tony as culpable. ${ }^{13}$ On the grounds that my preferred criminal law would view agents like Sam and Tony as acting culpably, Alexander et al. conclude that for

\footnotetext{
${ }^{11}$ Ibid., p. 658.

12 This is based on Alexander et al.'s analysis of the template that they number $(2) /(6)$. On the assumption that Sam believes that Sue has the attitude necessary for consent, and where 'A' denotes the attitude necessary for consent, and ' $\mathrm{C}$ ' denotes communication of consent, the Wanted Sex case is one in which the 'Facts' are 'A and $-\mathrm{C}$ ' and the 'Defendant's Beliefs' are 'A and $-\mathrm{C}$ '. With respect to such a case, Alexander et al. claim that I am committed to reforming the criminal law so that it views the act as 'wrong' and the agent as 'culpable'. Ibid., p. 659.

${ }^{13}$ The Unwanted Sex case is an example of the type of case that Alexander et al. number a '(4)/(8)' case. Where 'A' denotes the attitude necessary for consent, and ' $C$ ' denotes communication of consent, this is a case in which the 'Facts' are ' $\mathrm{A}$ and $-\mathrm{C}$ ' and the 'Defendant's Beliefs' are ' $\mathrm{A}$ and $-\mathrm{C}$ '. They claim that I am committed to reforming the criminal law so that it views the act as 'wrong' and the defendant as 'culpable'. Ibid., p. 659.
} 
'Dougherty, the defendant [in a case like Wanted Sex] is as culpable here as he is in [a case like Unwanted Sex], a quite problematic conclusion'. ${ }^{14}$

The appeal of Alexander et al.'s argument is limited by their reliance on the Wanted Sex case. In that case, Sue is actively resisting, and this feature may incline some people to support a criminal law that punishes Sam. To be charitable, we can strengthen Alexander et al.'s argument by offering them a less controversial case for their purposes:

Omission. Sid and Sara are sexually inexperienced. They intend to have sex with each other, conditional on the other also intending to have sex. They also intend to forego any moral complaint against the other for making sexual contact. However, they are both nervous and shy, and so do not attempt to communicate this willingness. Sid believes that Sara is willing to have sex with him, since he assumes that Sara will expressly refuse if she is unwilling. They have sex.

In this case, Sara does not engage in outward behavior that indicates she is willing to permit the sexual encounter. It is true that she does not protest, but I allow that these types of omission are too ambiguous to constitute consent. As a result, my view is indeed committed to holding that the sexual encounter is non-consensual. Still, we may be reluctant to view Sid and Tony in the same light, and we may have reservations about a criminal law that treats them in the same way. So if my view is committed to this equivalence, then that would be a reason to reject my view.

But I am not committed to viewing these cases in the same light. To respond to this objection, I propose that we distinguish two moral questions:

Permissibility Question. Does someone behave impermissibly?

Badness Question. How wrong or bad is someone's behavior?

While it is a binary matter whether an action is impermissible or not, it is a matter of degree as to how bad the action is. To illustrate the difference between these questions, consider Bert who intentionally steals a pear, and Ernie who intentionally murders an innocent person. Both Bert and Ernie act impermissibly. But Ernie’s behavior

${ }^{14} \mathrm{Ibid}$., p. 659 . At pp. $659-660$, Alexander et al. also argue that 'perhaps even more problematic' is my commitment to 'regarding the defendant as guilty of attempting nonconsensual sex' in a case with the following two features: (1) the patient has the requisite mental attitude e.g. of permitting the encounter, and has communicated her consent to the defendant; and (2) the defendant believes that the patient has that mental attitude and believes that the victim has not communicated her consent to the defendant. I pass over this argument on the grounds that it does not advance the debate beyond the initial standoff concerning whether communication is required for valid consent: if communication is required for valid consent, and the defendant does not believe that the patient has communicated, then there is no problem with viewing the defendant as attempting sex without valid consent. 
is much worse than Bert's. Consequently, we can say that Bert and Ernie are culpable in different ways: Bert is culpable for a much less serious wrong than Ernie is.

Once we have drawn this distinction, we can accept the Behavioral View of consent while recognizing that there are key moral differences between the Omission case and the Unwanted Sex case. This view entails that both Tony's and Sid's actions are impermissible, on the grounds that Sue and Teresa have not engaged in public behavior that indicates their consent. But we can accept this view while allowing that there are important gradations in the moral wrongness of various non-consensual interactions. We can consequently hold that different agents are morally culpable of acts that are wrong to differing degrees. We can claim that sexual activity without someone's consent is much worse when it is also against that person's will. The rationale for making this claim is that it accommodates the obvious moral differences between the Omission case and the Unwanted Sex case.

Now just as we can accept the Behavioral View while drawing moral distinctions between different impermissible actions, we can also propose that the criminal law should be sensitive to these distinctions. As we noted at the outset, a justification for punishing criminals is that they have performed actions that are morally wrong. This justification's attraction hinges on the punishment for an action being proportionate to the degree to which the action is wrong. So once we allow that there are moral gradations in the wrongness of the misconduct in the Omission case and the Unwanted Sex case, we should then frame the criminal law so that it imposes differential punishments on this misconduct.

Along these lines, there are two options open to us if we accept the Behavioral View. The first option is that we can hold that only Tony's behavior is so bad that it should be criminalized. That is, it is open to us to hold that while Sid's behavior is morally wrong, it is not so bad that it should be criminalized. After all, the criminal law does not sanction all morally impermissible behavior, even when this behavior wrongs another person. For example, wrongfully breaking a promise is not ipso facto a criminal offense.

The second option is that we can also hold that the criminal law should treat misconduct differently according to the degree to which 
the misconduct is morally wrong. For example, it could codify different offenses, with different punishments that are proportionate to the moral severity of each offense. ${ }^{15}$ It would not be ad hoc to do so, on two assumptions. The first assumption is that it is appropriate for the criminal law to track moral differences. ${ }^{16}$ The second assumption is that there is a clear moral difference between how bad Sid's and Tony's misconduct is. In the case of sexual offenses, the law could have two definitions of consent operating side by side. ${ }^{17}$ It could define 'behavioral consent' as 'a person's positive agreement, communicated by either words or actions, to engage in sexual intercourse or sexual contact'. And it could define 'mental consent' as 'a person's willingness to engage in a specific act of sexual penetration or sexual contact'. Corresponding to each definition, the law could specify two separate offences - an offence of sexual intercourse without mental consent and an offence without behavioral consent. On the grounds that the former is the more serious offence, the law could include sentencing rules that specify that the sanctions for the former offence are more stringent than the sanctions for the latter. If it did all these things, then the criminal law would sanction Tony in the Unwanted Sex case more punitively than it would sanction Sid in the Omission case. As a result, it would be treating both Tony and Sid as culpable, but it would not be treating Tony and Sid as equally culpable in the sense that it would not treat them both as culpable for committing equally grave wrongs.

\footnotetext{
${ }^{15}$ See Tom Dougherty, 'Affirmative Consent and Due Diligence', Philosophy and Public Affairs 46(1) (2018): 90-112. I leave open the possibility that there may be other ways of structuring the criminal law in this respect, e.g. combining both forms of misconduct into a single offense, while specifying different types of punishment for each type of misconduct. So long as the criminal law implies that instances of misconduct receive proportionate punishment, it may then be a matter of book-keeping which structure we prefer.

${ }^{16}$ I take this to be a plausible rationale for why the Model Penal Code distinguishes the offense of rape from the offense of aggravated rape.

${ }^{17}$ My proposal loosely tracks a superseded draft of the revisions to the Sexual Offences section of the Model Penal Code. At one point, a tentative draft defined a misdemeanor offence as occurring in the absence of 'a person's positive agreement, communicated by either words or actions, to engage in sexual intercourse or sexual contact', while defining separate felony offences in other terms. ALI The American Law Institute, https://www.ali.org/projects/show/sexual-assault-and-related-offenses/ (03/ 08/19). Ultimately, the American Law Institute Council decided at the 2016 annual meeting of the ALI against including a misdemeanor offence of engaging in sexual activity with someone who has not communicated consent, and instead defined consent in terms of 'a person's willingness to engage in a specific act of sexual penetration or sexual contact'. Jennifer Morinigo, 'Updated 'Consent' Definition', The ALI Advisor, December 19 2016, http://www.thealiadviser.org/sexual-assault/updated-consentdefinition/ (03/08/19).
} 
While both these options for framing the criminal law are open to us when accepting the Behavioral View of consent, I do not have a view as to which option is best. The right approach to constructing legislation should be informed by more than philosophy, and it is beyond my expertise to offer helpful guidance here. My point is that an advocate of the Behavioral View is not committed to the problematic conclusion that the Omission and the Unwanted Sex cases involve offences that are on a par.

But if we think that a more serious sexual offence is committed in Unwanted Sex than in Omission, then advocates of the Behavioral View need to make an important acknowledgment. If a less serious offence is committed in Omission, then it follows that the absence of behavioral consent is not sufficient for the most serious forms of sexual offence. ${ }^{18}$ Instead, the most serious forms of sexual offence occur only in the absence of mental consent - as per Unwanted Sex. So it is the absence of this mental consent that characterizes the most serious sexual offences. ${ }^{19}$

This concession may cast new light on the dispute between Alexander et al. and me. It can be helpful to bear in mind that there are multiple topics for which we might want to develop a conception of consent. In the philosophy of the criminal law, we need to articulate a type of consent whose absence is sufficient for the most

\footnotetext{
${ }^{18}$ Compare an argument of Ferzan's. Ferzan considers a case in which Jane is willing to let Jim use her pool, but Jim does not realize this. Ferzan notes that Jim would be 'disrespectful by using' Jane's 'pool without asking'. Still, Ferzan asks, 'But is this disrespect the primary wrong in rape? Or is the primary wrong that the boundary is crossed without the other person's willingness?' Ferzan 'Consent, Culpability, and the Law of Rape', p. 409.

${ }^{19}$ This conclusion matters for how we talk and think about sexual assault. Consider the following slogans:

(1) Consent is affirmative consent.

(2) Sex without consent is rape.

\begin{abstract}
'Affirmative' consent should be understood as requiring behavior that clearly indicates consent. It wouldn't be strange to see both slogans occurring in the same promotional campaign on a university campus, or for these claims to feature in an educational consent workshop for freshmen. But if we think that rape involves sexual activity against someone's will, then both claims can't truthfully be uttered in the same breath. If we endorse both claims (1) and (2) together, then they would entail that sex without a certain form of behavioral consent is rape. But that would imply that a rape occurs in the Omission case. That implication is inconsistent with the assumption that rape involves sexual activity that is against the victim's will. In light of the conclusion reached in the main text, we would need to make this assumption if we wish to use the term 'rape' to pick out the most serious sexual offenses. But if we make that assumption, then to interpret claims (1) and (2) charitably, we have to see each claim as invoking a different conception of consent. Claim (1) is true only if we conceive of consent as behavioral consent. Meanwhile, claim (2) is true only if we conceive of consent as mental consent. This leaves us with a dilemma. Either we think of consent as mental consent, in which case we have to deny (1), or we think of consent as behavioral consent, in which case we have to deny (2). We can't have it both ways.
\end{abstract}


serious forms of sexual offense. ${ }^{20}$ Meanwhile, in normative ethics, we need to articulate a type of consent whose absence is typically sufficient for an action to be impermissible. ${ }^{21}$ Since actions can be impermissible, while only being a little wrong, these are different projects. With respect to the former project, everyone can agree that the absence of mental consent plausibly plays the role of demarcating the most serious sexual offences. But there remains room for disagreement about whether mental consent or behavioral consent makes the difference as to whether an action is permissible. To resolve this disagreement, we cannot make progress simply by noting that the behavior for which Tony is culpable in Unwanted Sex is much worse than the behavior for which Sid is culpable in Omission. That observation bears only on the aforementioned Badness Question and does not speak to the Permissibility Question. Yet it is how to answer the Permissibility Question that is the point of dispute between the Mental and Behavioral Views of consent.

\section{ARGUMENT 2: ABANDONMENT WITHOUT COMMUNICATION}

The second argument that I want to consider involves drawing an analogy between abandonment and consent. Alexander (2014) and Ferzan (2016) hold that abandoning property does not require any outward behavior; instead, it requires only a mental choice. The rough idea is that you have abandoned a bicycle if and only if, under suitable conditions, you have decided to give up this bicycle. ${ }^{22} \mathrm{We}$ can call this the 'Mental View' of abandonment.

Alexander and Ferzan propose an analogy between consent and abandonment, and use this analogy to argue that consent is also mental. Alexander argues as follows:

...let me try further to bolster my view that consent is a mental state and requires no signification and no particular uptake of the signification. I will do so by reference to the legal notion of abandonment.

\footnotetext{
${ }^{20}$ There is also the possibility that we need to articulate multiple types of consent, whose absence is sufficient for different sexual offenses. This would be to adopt the second option that I proposed in the main text.

${ }^{21}$ If a patient's consent is needed for an action, then the absence of her consent would be a pro tanto reason in favor of the action being impermissible. In typical cases, this reason will win the day. But there are atypical cases in which a greater benefit to the patient or a third-party constitutes sufficient justification for the action being all things considered permissible. Thanks to Alec Walen for this point.

${ }^{22}$ As with the Mental View of consent, this rough idea can be made more precise by giving a more specific account of what constitutes the mental attitude for abandonment.
} 
Someone who has the legal status of being the owner of some item of property can alter that status in several ways, one of which is by abandoning the property. And one can abandon one's property by changing one's mental state vis-à-vis that property. For example, suppose Jane is tired of her balky lawn mower. So she leaves it in her driveway, intending never again to assert ownership of it. She has, as a matter of law, effectively abandoned the lawn mower. If Jim comes along and takes it, he has not committed theft. For the lawn mower is now unowned. Indeed, when Jim takes it, with the intention to assert dominion and control over it, he has become its owner.

Now suppose when Jim takes the lawn mower he does not believe Jane has abandoned it. (Jane frequently leaves the lawn mower in the driveway.) If Jim, acting with this belief, nonetheless takes the lawn mower, he has acted culpably. Indeed, he has attempted theft. But he is not a thief, for he did not take another's property.

The essence of abandonment is a mental state. External actions can only signify abandonment. They do not constitute it. The same is true of consent, or so I contend. ${ }^{23}$

\section{Since Alexander intends for this argument to 'bolster' the Mental} View of consent, I interpret him as relying on the premise that there is some reason to believe that the truth of the Mental View of abandonment would make more plausible the Mental View of consent. His other premise is that the Mental View of abandonment is true. Together, these premises would support the Mental View of consent.

Ferzan argues along similar lines in the context of responding to my view that the normative power of consent is similar to the normative power of promise in the respect that both powers require communication. ${ }^{24}$ Ferzan's argument begins:

In contrast, abandonment seems perfectly consistent with a mental act view. As Eduardo Peñalver notes, "[r]ather than understanding this physical separation as an essential component of the legal concept of abandonment, however, it would be more accurate to view the intent unilaterally to terminate rights as definitive of abandonment[.]" Although it is admittedly more difficult to abandon property that is on your own property, the idea that merely by choosing to leave your bicycle unclaimed, you can renounce your rights seems correct. A person who then took "your bike" would not be taking the property of another because you had relinquished your right to it - irrespective of whether you said or did anything to so communicate your abandonment. (If the person believed he was stealing your bike, he might be liable for an attempt. More on that possibility below.) Of course, even if the normative power of abandonment requires only the decision to relinquish one's rights, the law might adopt prophylactic rules. Indeed, property abandonment is heavily regulated because of evidential concerns. The legal system requires both an intention to abandon and an act of relinquishment.

At this point, the goal of the discussion is simply to argue that the idea of a normative power need not entail a communication. If one thinks that one can abandon without communication, there is no reason one cannot likewise consent in a similar way. To understand consent as a normative power, then, does not require us to understand consent as something that is expressed. $^{25}$

${ }^{23}$ Alexander, 'The Ontology of Consent', p. 107.

${ }^{24}$ Dougherty, 'Yes Means Yes'.

${ }^{25}$ Ferzan, 'Consent, Culpability, and the Law of Rape', p. 404, (citing Eduardo Peñalver, 'The Illusory Right to Abandon', Michigan Law Review 109(2) (2010): 191-219, p. 197). 
At this stage in her argument, Ferzan's conclusion is modest: she claims that the mere fact that consent is a normative power does not show that it requires communication. But later, Ferzan draws on the connection with abandonment to argue positively for the view that consent is mental. Ferzan continues that the power to abandon is tied to our autonomy. Our lives would be quite encumbered if we could not choose to sever relations with things we no longer wish to have'. ${ }^{26}$ Ferzan argues that consent plays a similar role in promoting our autonomy, by allowing us to determine who can cross our boundaries. Consequently, Ferzan concludes that ' $[\mathrm{t}]$ he reason to think consent is more like abandonment than promising, then, is that we think the internal choice view respects the autonomy that grounds consent and that this view reflects when the putative victim experiences that she is or is not wronged, ${ }^{27}$

I am unmoved by the argument from abandonment. Neither Alexander and Ferzan offer any argument in favor of the Mental View of abandonment, besides Ferzan's argument that a mental power of abandonment serves our interest in autonomously deciding whether we have property. ${ }^{28}$ (I will respond to this argument shortly.) I assume that the charitable interpretation for this scarcity of argument is that Alexander and Ferzan expect that everyone will find intuitively attractive the Mental View of that abandonment. If so, then I am afraid that their expectations are disappointed in my case. In the abstract, I find at least as appealing the 'Behavioral View' of abandonment. Like the Behavioral View of consent, the Behavioral View of abandonment can - but need not - require a mental attitude on the part of the abandoner. It differs from the Mental View of abandonment by claiming that some behavior is required. I think that a plausible version of the Behavioral View would focus on the property-owner's sum total of behavior, and require from this some indication of abandonment. An easy way for someone to indicate abandonment would be to explicitly declare that she is abandoning an object. But this indication could also be achieved implicitly through certain omissions. If the sum total of the indi-

\footnotetext{
${ }^{26}$ Ibid., p. 405.

${ }^{27}$ Ibid., p. 407.

${ }^{28}$ In support of her view, Ferzan approvingly cites Peñalver, 'The Illusory Right to Abandon'. Peñalver's essay concerns the legal perspective on abandonment, and does not discuss the morality of abandonment. While Peñalver does assert that from a legal perspective the Mental View of abandonment is correct, he does not supply any grounds for this assertion.
} 
vidual's behavior includes her omitting to claim some object as her own over a period of time that is long enough that she could reasonably be expected to claim the object during this period, then this extended omission can be reasonably interpreted as indicating abandonment. This contrasts with the Mental View of abandonment, which does not require any extended omission for abandonment. The Mental View implies that the individual abandons the object when she decides to abandon it.

I said I find the Behavioral View of abandonment more plausible in the abstract than the Mental View. We can also sharpen the debate by considering concrete cases in which someone changes her mind about abandoning property. When we do, I think the Behavioral View of abandonment has a clear advantage. Consider:

Forgotten Scarf. Ian messages Harriet to tell her that she has left her scarf at his party. Harriet does not reply to the message. On the grounds that it is not worth the effort of travelling to pick up the scarf, she decides to abandon it. Later, she comes to think she is being lazy and changes her mind. She messages Ian asking to arrange a time to pick up the scarf.

When messaging Ian, Harriet is able to lay claim to the scarf. She is not simply asking him to give her the scarf. She is entitled to claim it as her property. That entitlement requires that she remains the rightful owner of the scarf at that point. However, the Mental View of abandonment mistakenly implies the reverse. According to that view, Harriet's earlier decision would have constituted abandonment. But a characteristic feature of abandonment is its finality: once something is not your property, you have no special ability to claim this thing as your own. So it would then follow that Harriet cannot later re-assert her claim to the scarf when she messages Ian. Since Harriet can lay claim to the scarf when messaging Ian, the Mental View of abandonment is false. In just the same way that your mere decision to make a promise does not bind you so long as you have not yet indicated this decision, your mere decision to abandon property is not binding either. With both promises and abandonment, you are free to change your mind, up until the point at which you indicate your decision.

We can also draw on the Forgotten Scarf case to challenge Ferzan's claim that the Mental View of abandonment is supported by the consideration that the power to abandon is tied to our autonomy. As we can see from the Forgotten Scarf case, the Mental View would make Harriet less autonomous in a respect: it would imply that once 
she has made her decision, she is no longer able to change her mind and claim the scarf as her property. In that respect, the Mental View is limiting Harriet's ability to control who owns the scarf. By contrast, the Behavioral View of abandonment increases Harriet's autonomy by giving her this ability. It gives her freedom to change her mind, so long as she has not yet publicly committed herself. This freedom will be valuable to her in light of the possibility that she comes to see her previous decision as mistaken. This possibility is realized in the Forgotten Scarf case, where Harriet comes to think that she had previously been lazy when she initially decided to abandon the scarf.

It is true that the Behavioral View implies that Harriet's autonomy is limited in the respect that she cannot shed the property through a mental decision alone. But that does not imply that her life 'would be quite encumbered' in virtue of her not being able to 'choose to sever relations with things' she 'no longer wished'. ${ }^{29}$ Harriet will not be encumbered precisely because she is no longer in physical possession of the scarf. Moreover, she will not be further laid down with additional efforts to tell all and sundry that she has given up her claim to the scarf. According to the version of the Behavioral View of abandonment that I sketched above, simply omitting to claim the scarf will eventually constitute a public indication of abandonment. This omission will not be particularly taxing of Harriet, and requiring it for abandonment does not meaningfully limit her ability to get rid of property that she no longer wants. And so, the Behavioral View's limit to Harriet's autonomy is trivial. In light of these points, I conclude that considerations of autonomy favor the Behavioral View of abandonment over the Mental View.

Moreover, the Behavioral View of abandonment is the one typically taken by the law. As Ferzan notes in the quotation above, presumably with the United States in mind, the 'legal system requires both an intention to abandon and an act of relinquishment'. ${ }^{30}$ This would seem as clear an indication as you might like that the law employs a Behavioral View of abandonment. To dismiss this interpretation of the law, Ferzan claims that this requirement is simply a 'prophylactic rule' grounded in 'evidentiary concerns'. But that is a

\footnotetext{
${ }^{29}$ Ferzan, 'Consent, Culpability, and the Law of Rape', p. 405.

${ }^{30}$ Ibid., p. 404.
} 
tendentious characterization of the law, and in the absence of a good argument for the Mental View of abandonment, it is hard to see why we should prefer this characterization over the simpler and more natural interpretation that the law simply takes an act of relinquishment to be constitutive of abandonment.

This leaves Ferzan's and Alexander's Mental View of abandonment vulnerable to a different line of attack. If certain parts of the ethics of property are conventional, and the norms concerning abandonment are among these parts, then the ethics of abandonment will be determined by the social or legal conventions that are operative. For example, if our society's social and legal conventions embody a Behavioral View of abandonment, it would then follow that, in our society, abandonment requires public behavior.

This brings us to a big picture controversy about the extent to which the ethics of property are conventional. One view is that the ethics of property are entirely non-conventional: every fact about who morally owns what, and what each person morally may do with what, is determined independently of conventions. A second view is that the ethics of property are entirely conventional: in a society, every fact about who morally owns what, and what each person morally may do with what, is determined solely by the conventions in that society. A third view is that some parts of the ethics of property are determined by convention, and other parts are determined non-conventionally. For example, one could hold that the non-conventional parts of the ethics of property leave many moral details indeterminate, and these indeterminacies are to be resolved through social and legal conventions. Who inherits legal title to the property of someone when she dies intestate? Which forms of consideration, if any, must each party exchange in order for a legal contract for the exchange of goods and services to be binding? Since it is hard to believe that these questions have answers in the state of nature, the first view - that the ethics of property are entirely nonconventional - looks implausible. If so, then we should assume that the ethics of property are partly, if not entirely, conventional.

Since the second view - that the ethics of property are entirely conventional - is unfriendly to Alexander's and Ferzan's Mental View of abandonment, let us assume for the sake of argument that the third view is true. Assuming that some issues in property ethics 
are conventional and others are not, which issues should we expect to fall on each side of this distinction? The most plausible candidates for the non-conventional side include issues where there is a strong $a$ priori argument from justice that someone has a property right. For example, from the fact that I took the efforts to pick the berries from the thorny bush in the state of nature, it may seem just that I get to enjoy the fruits of my labor. But the more complex the issue, and the more it requires weighing together potentially incommensurable considerations, the more plausible it is that we will need a social or legal convention for a determinate result.

Cast in this light, there is a strong case for abandonment being conventional. This is what is suggested by Peñalver's discussion of abandonment, which Ferzan cites approvingly. ${ }^{31} \mathrm{I}$ will not try to summarize the substance of Peñalver's account here, but instead will simply note that one of its key take-home messages is that the legal doctrine of abandonment is highly complex. The doctrine draws important distinctions between abandoning chattels and abandoning land, and embodies a host of legal rules that reflect various considerations, including considerations of which rules would be most efficient. As such, abandonment brings into play just the complexity that would lead us to expect it to receive a conventional treatment. But if abandonment is conventional, then we should turn to the conventions in our society to determine whether abandonment requires public behavior. These could be legal conventions, or informal social conventions. Although I am not able to argue for this claim here, my sense is that in our society only our legal conventions are sufficiently extensive and specific to navigate the complexities concerning abandonment. If that is right, then the Mental View of abandonment comes unstuck in light of the fact that our society's legal conventions are that abandonment requires public behavior.

In light of our detour via the ethics of property, we may now wonder about one of the standard assumptions underlying the debate between the Mental View and the Behavioral View of consent. Typically, that debate is pitched on the assumption that one view is uniquely right for all types of consent, and for all societies. But that assumption may be challenged. Consider consent to the use of impersonal property. Perhaps, the ethics of this type of consent are

\footnotetext{
${ }^{31}$ Peñalver, 'The Illusory Right to Abandon'; Ferzan, 'Consent, Culpability, and the Law of Rape', p. 404.
} 
among the ethics of property that are determined conventionally. If so, we might need to look, on a case by case basis, at each society's conventions concerning this type of consent. For example, we might need to turn to the statutes to determine whether a landowner's public behavior is necessary to entitle strangers to roam across her rural property.

I cannot resolve here whether it is right to see as conventional some parts of the ethics of consent to the use of property. But for the sake of argument, let us suppose that some parts are. This assumption should make us wary about inferences from the ethics of property consent to the ethics of bodily consent. Just because there are reasons to expect tenancy agreements to be conventional, it does not follow that these reasons will similarly motivate the idea that how an individual controls her bodily domain is also conventional. In particular, many of us will find implausible the idea that our sexual rights are conventional to a significant degree. ${ }^{32}$ Regardless of whether we are in this society, that society, or a state of nature, the moral facts concerning sexual consent seem largely invariable. But if there is no connection between sexual consent and property consent, then there seems equally no connection between the ethics of sexual consent and the ethics of abandonment. If so, then whatever we say about abandonment, we should conclude little about the ethics of sexual consent. So not only does Alexander's and Ferzan's argument rely on a mistaken view of abandonment, it may also be that any argument concerning abandonment will teach us little about the ethics of sexual consent.

\section{CONCLUSION}

I will conclude by briefly summarizing my responses to the two arguments that we have considered.

\footnotetext{
${ }^{32}$ Not everyone agrees—see David Owens, Shaping the Normative Landscape, (Oxford: Oxford University Press, 2012). Meanwhile, Japa Pallikkathayil argues that other bodily rights are conventional. Japa Pallikkathayil, 'Persons and Bodies', in Freedom and Force: Essays on Kant's Legal Philosophy, eds. Sari Kisilevsky, (Martin Stone, Oxford: Hart Publishing, 2017). An anonymous reviewer has suggested that what constitutes appropriate communication of a willingness to take part in sexual conduct is at least partially conventional. An advocate of the Behavioral View could acknowledge this role for conventions, while denying that conventions play any further role in structuring our sexual rights. However, my own view is that conventions play only a limited role in this communication, because circumstantial evidence can make it clear that the conventional interpretation of an utterance is not the correct interpretation.
} 
The first argument, by Alexander et al., was that, as an advocate of the Behavioral View, I am problematically committed to treating as equally culpable an actor who imposes sexual activity on someone against her will and an actor who imposes sexual activity on someone who welcomes the activity but fails to communicate this. ${ }^{33}$ This objection fails because the allegation that I am committed to treating these actors the same is spurious. If we accept the Behavioral View, then we are free to hold that while both actors are culpable for acting impermissibly, one is culpable for acting much worse than the other. Similarly, we are free to propose either that the criminal law imposes different sanctions for each act, or that the criminal law imposes sanctions only on sexual activity that is against someone's will.

The second argument, by Alexander and Ferzan, was based on an analogy between abandonment and consent: just as we should accept the Mental View of abandonment, so we should accept the Mental View of consent. ${ }^{34}$ In response, I have argued that the Mental View of abandonment is false, on the grounds that it fails to accommodate the fact that people are free to change their minds about whether they are abandoning their property, so long as they have not publicly expressed these decisions. Moreover, the Mental View of abandonment runs contrary to the law's standard position on abandonment, which requires public behavior. Insofar as it is plausible to think that legal conventions determine the ethics of property, this gives us reason to accept the Behavioral View of abandonment. Meanwhile, the ethics of sexual consent are nonconventional. So if the ethics of abandonment are conventional, then we should not make inferences from the ethics of abandonment to the ethics of sexual consent.

\section{OPEN ACCESS}

This article is distributed under the terms of the Creative Commons Attribution 4.0 International License (http:// creativecommons.org/licenses/ by $/ 4.0 /$ ), which permits unrestricted use, distribution, and reproduction in any medium, provided you give appropriate credit to the original author(s)

\footnotetext{
${ }^{33}$ Alexander et al., 'Consent Does Not Require Communication'. Dougherty, 'Yes Means Yes'.

${ }^{34}$ Alexander, 'The Ontology of Consent'. Ferzan, 'Consent, Culpability, and the Law of Rape'.
} 
and the source, provide a link to the Creative Commons license, and indicate if changes were made.

Faculty of Philosophy,

University of Cambridge, Sidgwick Avenue, Cambridge, CB3 9DA, UK

E-mail:tom.dou@gmail.com

Publisher's Note Springer Nature remains neutral with regard to jurisdictional claims in published maps and institutional affiliations. 